\title{
Hombres de saber y de acción en tiempos convulsionados: imaginarios y lenguajes sobre el orden político en Charcas. (Desde las reformas borbónicas hasta la Asamblea del Año XIII)*/
}

Men of Learning and Action in Convulsive Times: Imaginary Languages and the Political Order in Charcas. (From the Bourbon Reforms to the Assembly of Year XIII)

\author{
Esteban De Gori \\ Consejo Nacional de Investigaciones \\ Científicas y Técnicas (CONICET) \\ Universidad de Buenos Aires
}

El trabajo se propone analizar los imaginarios y lenguajes sobre el orden político que se elaboraron en el territorio de la Audiencia de Charcas en el periodo que va, fundamentalmente, desde las reformas borbónicas hasta la instalación de la Asamblea del Año XIII. El objetivo del mismo, busca presentar la pugna y reformulación de los diversos imaginarios a través de la relación entre coyuntura y discurso.

PALABRAS ClaVes: Hombres de saber; Poder, imaginarios y lenguajes políticos; Reformas borbónicas; Asamblea del año XIII.

The paper analyzes the imaginary and the political order languages that were developed in the territory of the Audiencia de Charcas in the period mainly from the Bourbon reforms to the installation of the Assembly of Year XIII. Its objective, seeks to present the struggle and reformulation of various imaginary through the relationship between climate and discourse.

KEYwORDS: Men of knowledge; Power, and political imaginary languages; Bourbon reforms; Assembly of Year XIII.

* Este trabajo fue presentado en el IX Congreso Internacional de Etnohistoria, «Colonización, descolonización e imaginarios», Arica, Chile, 11-14 de noviembre de 2014. 


\section{Introducción}

El trabajo se propone investigar los imaginarios y lenguajes sobre el orden político que se elaboraron en el período que va desde las reformas borbónicas a la instalación de la Asamblea del Año XIII. ${ }^{1}$ Para ello, se analizarán los documentos de Victorián de Villava, Mariano Moreno, Matías Terrazas y Benito Moxó y Francolí, así como las proclamas, documentos de funcionarios y pasquines que se realizaron durante la crisis de la monarquía. Si bien en un trabajo in extenso deberían analizarse las intervenciones de otros letrados u hombres de saber, creemos que estos textos seleccionados pueden dar cuenta de los debates y pugnas en dicho período. A modo de hipótesis de trabajo, sostenemos que el periodo de tensiones y crisis que se condensan entre mediados del siglo XVIII y principios del XIX empujaron a los hombres de saber a buscar entre los imaginarios y lenguajes políticos que habitaron el universo simbólico de la monarquía hispana aquellas concepciones y vocabularios que entendieron como eficaces para lograr la adhesión y lealtad a un orden, ya sea para reformarlo, conservarlo o trastocarlo. A su vez, sostendremos que las «coyunturas críticas» se presentaron como momentos oportunos para la escritura, como para una intervención que buscó efectos performativos en el terreno político e imaginario.

En relación al periodo seleccionado, nos proponemos analizar una coyuntura previa ya que «entre 1750 y 1850 los modos de legitimación y representación del poder público en nuestras sociedades se transformaron profundamente». ${ }^{2}$ Es decir, se dieron algunos conflictos, crisis y otros sucesos que llevan a los actores a indagar sobre la viabilidad o no del orden político.

Como observaremos, las trayectorias de los discursos, como las de los imaginarios, no son lineales, sino que están sujetas a la compleja dinámica política y a las decisiones prácticas que los grupos y la «gente de saber» ${ }^{3}$

1 Congreso Constituyente convocado en el año 1812 por el Segundo Triunvirato. Este órgano, formado en Buenos Aires, tenía como propósito la organización del poder revolucionario, la cohesión territorial — teniendo en cuenta los límites del virreinato del Río de la Plata- y la legitimación del nuevo orden. Para ello, se decidió la elección de diputados de las provincias y territorios. Entre estos se encontraban los que correspondían a la Audiencia de Charcas.

2 Fernández Sebastián, 2009, 37.

3 Tomaremos este concepto o bien el de «hombre de saber» considerando la reflexión de Mazín (2008), ya que este autor considera que es «un término justo» frente al concepto de intelectuales. 
asumen en momentos de disputa y confrontación. En los textos y documentos no solo habitan los debates de su época, sino los propósitos de los actores individuales y colectivos. A esta reflexión habría que añadirle una consideración final: aquella que nos advierte que los agentes, en su vida política, asumen posiciones que no son siempre iguales a sí mismas ya que estas se encuentran íntimamente vinculadas a los cursos de acción establecidos por los grupos que integran o en los cuales se consideran representados. En este sentido, entendemos que es posible presentar cómo los letrados y hombres de saber se apropiaron, articularon y resignificaron imaginarios y concepciones políticas sobre el orden político para fundamentar sus propuestas y las de las élites políticas a las que pertenecían o las que comenzaban a afirmarse en el escenario político.

\section{Escritura y hombres de saber}

Los hombres de saber, a partir de mediados del siglo XVIII en Hispanoamérica, desempeñaron un papel relevante en la presentación y resignificación de imaginarios y discursos. Se constituyeron en actores claves en la circulación de ideas y de propuestas y se consolidaron en referentes del mundo letrado. De hecho, durante los conflictos, tensiones e intervenciones que las propias reformas borbónicas suscitaron sobre el orden colonial y sus instituciones estos hombres de saber se afianzaron o asumieron un lugar relevante.

Las nuevas condiciones políticas y económicas que supusieron las reformas borbónicas —entre otras: la presión fiscal, la afirmación de la voluntad regia y el desequilibro de poderes entre funcionarios y élites locales- permitieron la creación de un renovado clima intelectual. Como advierte Jorge Myers:

si bien el pleno florecimiento de los «gens de lettres» y los «gens de savoir» de la ilustración española recién se daría en el marco - y sobre todo como consecuencia posterior a su implantación — de las llamadas «reformas borbónicas» iniciadas en el reinado de Carlos III (1759-1788) y esporádicamente continuadas por su sucesor -Carlos IV (1788-1808)-, los primeros signos de un cambio de clima intelectual profundo se hicieron sentir ya desde mediados del siglo XVIII. ${ }^{4}$

4 Myers, 2008, 33. 
Este nuevo clima intelectual estaba vinculado a las transformaciones que los Borbones introdujeron en un sistema político que había imperado por más dos siglos y que se basaba, como demuestran Fradkin y Garavaglia, en el consenso que el imperio tenía entre los grupos de élite coloniales. ${ }^{5}$ Esta búsqueda por reformular los términos del orden político - situación que va a desestabilizar viejos equilibrios sociales- permitió no solo la afirmación y un renovado rol de los hombres de saber, sino un universo de intervenciones y documentos sobre el mismo. Es decir, los intentos borbónicos por redefinir el orden y establecer nuevos consensos abrieron trayectorias discursivas y prácticas de legitimación o resistencia que quedarían cristalizadas en diversos documentos.

Los textos de funcionarios de la Audiencia de Charcas y de su tribunal, de clérigos, de miembros de la Universidad, así como los anónimos se convirtieron en «territorios» habitados por la articulación de diversos imaginarios y vocabularios políticos, intentando así construir campos discursivos, propuestas, establecer distinciones e indicar su espacio de referencia. En este sentido, los autores que seleccionamos en este estudio participarán en el debate político y en ese proceso se constituirán como parte integrante de los campos en disputa. Estos hombres de saber, como indica Baczko, intentaron marcar

su «territorio» y las fronteras de este, definir sus relaciones con los «otros», formar imágenes de amigos y enemigos, de rivales y aliados; del mismo modo significa conservar y modelar los recuerdos pasados, así como proyectar hacia el futuro sus temores y esperanzas. ${ }^{6}$

La argumentación como «artefacto de intervención» y como pedagogía política, no solo buscará la formación de una opinión pública, sino que perseguirá la adhesión y lealtad tanto de actores gravitantes como subalternos para modificar o conservar algunas prácticas. En esta búsqueda, la capacidad de algunos hombres de saber se «jugará» en la posibilidad de multiplicar y forzar imaginarios, memorias, transposiciones, experiencias y representaciones.

Los hombres de saber que estudiaremos elaboran — desde las reformas borbónicas hasta la crisis de la monarquía (1808) — una mirada sobre el orden político, manteniendo como «cuerpo ineludible» del debate al

5 Fradkin y Garavaglia, 2009, 191-192.

6 Baczko, 1999, 28. 
cuerpo regio. En este sentido, con el cautiverio del rey (1808) y la polémica sobre la legitimidad de las autoridades coloniales, observaremos la disputa entre imaginarios y «vocabularios de la soberanía», los cuales se van a constituir en los signos demostrativos de las pugnas políticas. De esta manera, las experiencias de las juntas de La Plata y La Paz en 1809 y su impugnación implicaron, entre otras cosas, que la intervención de los hombres de saber se dirigiera a recrear la legitimidad de las acciones en pugna. Para ello, esa intervención se valió, como indicaba Baczko, «de instrumentos de persuasión, de presión, de inculcación de valores y creencias». Entonces, el uso de lo propiamente simbólico, de las representaciones y de lo imaginario se tornó relevante para las disputas políticas abiertas con las reformas borbónicas, la insurgencia indígena liderada por Túpac Amaru y Túpac Katari y la instalación de las juntas. Es decir, había que construir una «hermenéutica» del conflicto y dotar de interpretación a las posibles consecuencias. En el caso del Alto Perú, los hombres de saber en este periodo estudiado se valieron, al modo en que el conflicto lo suscitaba y requería, de los vocabularios del autogobierno, como del regalismo borbónico e inclusive se apropiaron de las metáforas bíblicas para elaborar adhesiones y consensos con otros actores. De algún modo, utilizaron aquellas metáforas, vocablos y representaciones que habitaron el universo político de la monarquía hispana para legitimar sus acciones y la conservación o reformulación de un orden en crisis.

\section{Victorián de Villava: mita y reforma del vínculo imperial}

El intento de llevar adelante las reformas proyectadas por la casa de los Borbones va a plantear diversas propuestas y respuestas a ambos lados del Atlántico. Algunos funcionarios, como es el caso de Victorián de Villava, van a intervenir desde los territorios americanos planteando una reforma de la monarquía, pero también acerca de las condiciones de trabajo a la que eran sometidos los indios.

En 1793 Victorián de Villava escribiría el Discurso sobre la mita de Potosí en respuesta a un nuevo código sobre la mita encargado por Francisco de Paula Sanz — gobernador intendente de Potosí- a su asesor

7 Baczko, 1999, 31. 
Vicente Cañete. ${ }^{8}$ Estos últimos buscaban aumentar la extracción minera, dotar a las empresas mineras de contingentes de indígenas en situación de trabajo forzoso, incrementar la presión fiscal y, por ende, coaccionar y limitar la autonomía de las comunidades indígenas.

El debate entablado entre Villava y Paula Sanz tendrá una profunda resonancia entre los hombres de saber y en los futuros abogados, ya que se recuperaban las discusiones - fundamentalmente en relación con la autonomía de la comunidad y sobre la presión laboral y fiscal- que las sublevaciones indígenas habían dejado planteadas después de su derrota. La memoria de esos conflictos había quedado como la memoria de discusiones pendientes que ahora «emergían con cierta intensidad». Diez años después de las derrota de los Amaru y los Katari (1782), el fiscal de la Real Audiencia criticaba a la mita advirtiendo que:

1ro. Que el trabajo de las minas de Potosí no es público.

2do. Que aun siendo público no da derecho a forzar a los indios.

3ro. Que el indio no es tan indolente como se piensa.

4to. Que aun siendo indolente en sumo grado no debe obligarle a este trabajo con coacción. ${ }^{9}$

Esta defensa jurídica de Victorián de Villava le auguraría un enfrentamiento político con Sanz y una rápida respuesta que apareció con el nombre de Contestación (1794). En este documento no solo se justificaba la utilidad pública de la mita, sino que esta debía garantizarse con el trabajo forzado de los indios, el cual, en última instancia y según su concepción, se tornaría ventajoso para el mismo indio.

En esta controversia podemos observar que mientras Villava defendía los derechos de los indios-vasallos frente a los intereses de aquellos que explotaban los yacimientos mineros; Francisco de Paula Sanz reivindicaba las necesidades estatales de aumentar el erario público y el control político sobre las comunidades a través del trabajo forzado de los indios. Entonces, se polemizaba en torno a las formas de lograr el bienestar público y, además, acerca de la gobernabilidad de los indios. La extracción de minerales, según Sanz, se convertía en la única ratio de riqueza del orden político, la cual se volvía una forma efectiva de dominio sobre las comunidades

8 El código carolino de ordenanzas reales de las minas de Potosí y demás provincias del Río de la Plata (elaborado entre 1792 y 1794). Este código no llegó a aplicarse por las polémicas que suscitó.

9 Villava, «Discurso sobre la mita de Potosí», 1793, en Levene, 1946, XXXI. 
indígenas. Es decir, la presión por intensificar la mita se daba de bruces con las mayores cuotas de autonomía que venían reclamado los indios desde la insurgencia de $1780 .{ }^{10}$ Para Villava, la mita era contraria a los intereses de la Corona - ya que esta debía resguardar su bien más preciado que era su reino-, a las leyes y, por lo tanto, a la utilidad pública y a la gobernabilidad. Es decir, dicho fiscal expresaba una moral imperial distinta a la esgrimida por Paula Sanz, una moral humanista que vinculaba la utilidad pública y riqueza del Estado, ya no a la minería sino a la agricultura y el comercio. Entonces, la polémica sobre la mita dejaba de ser una discusión técnica para transformarse en el enfrentamiento de dos «morales» acerca del poder, acerca del bienestar público y, por último, acerca de la condición de los indios y del orden político.

En 1797, el fiscal Victorián de Villava desarrolló sus Apuntes para una reforma de España, sin trastorno del Gobierno Monárquico ni la religión. Su escritura se encuentra influenciada por los debates que abren los procesos revolucionarios en las ex Trece Colonias y en Francia, así como por los diversos programas de reformas que llevan adelante varias monarquías (Inglaterra, Reino de las Dos Sicilias, Prusia).

En su texto, Villava manifiesta que se encuentra motivado por la necesidad de otorgarle un «nuevo ser» a su nación para que no quede sometida a los trastocamientos políticos acaecidos en el mundo presente:

En una época en que el espíritu de libertad hace tantos progresos, y que el entusiasmo que le subsigue hace tantos estragos, debe todo buen ciudadano dedicar sus meditaciones a evitar una revolución, que los mismos abusos preparan, que el ejemplo de los demás pueblos anticipa, y que debe temerse más que los males que padecemos, y tanto deseamos enmendar. ${ }^{11}$

En este sentido, el fiscal propuso repensar el orden monárquico y enmendar esos abusos que prepararían la revolución. Da cuenta de los desequilibrios producidos por las reformas borbónicas, insistiendo en una interpretación del orden político y manifestando que «nuestro actual estado es violento, y que nada violento es durable; que si discurro medios para la subsistencia de la Monarquía y de la Religión, antes que los abusos de ambas acaben con las mismas...». ${ }^{12}$ Los abusos mismos de los funcionarios Godoy, 1995.

10 Sobre la insurgencia indígena de 1780 ver Serulnikov, 2010; Walker, 1999; O'Phelan

11 En Levene, 1946, 98.

12 Ibidem, 101. 
de la monarquía y de la Iglesia podían destruir y erosionar a estas mismas instituciones. De esta manera, los abusos de los que mandan aparecen como una clave de lectura para reflexionar sobre la estabilidad o la posible disolución del orden.

La corrección de los abusos y excesos suponía asumir que la reforma de la monarquía podía frenar cualquier trastocamiento político y la posibilidad de la revolución en España y la consiguiente independencia de América. En este sentido, reforma y estabilidad aparecen como ideas comunes de un pensamiento que devela los problemas políticos del poder monárquico. Reformar suponía, para Victorián de Villava, limitar las fuerzas excesivas y entusiastas de la política y de la historia, provengan del soberano - y de sus funcionarios- como del pueblo mismo. Es decir, había que sustraerle aquella desmesura de los viejos tiempos (el despotismo monárquico) y la de los nuevos (las propuestas democráticas). De esta manera, Villava buscaba reconducir y conciliar la voluntad regia con un programa de reforma.

El espíritu reformista aparece bajo el lenguaje de la advertencia a la Península, a su monarca y funcionarios, ya que una mudanza de gobierno en términos violentos desataría una catástrofe política para la monarquía. Sobrevendría la independencia y el surgimiento de «un déspota que probablemente cerraría sus puertas con España». ${ }^{13}$ Para ello, Villava esgrime una fórmula política diferenciada de los regalistas: «contentémonos con moderar la monarquía de modo que sin disminuir la felicidad personal del monarca aumentemos la nuestra». ${ }^{14}$

En este sentido, Villava integraba una las perspectivas que había suscitado el impulso reformador imaginado por los Borbones. Por tanto, podríamos plantear que se inauguraban dos lecturas diferentes acerca de la reforma del orden político: una, que reafirmaba la voluntad absoluta del rey como motor de cualquier reforma y que centraba la idea de modernización ${ }^{15}$ en la racionalización de la burocracia; otra, que recuperaba las tradiciones constitucionales (como la aragonesa y la napolitana) y que entendía que el proceso de modernización suponía el reconocimiento de los derechos de poderes locales (y de sus autonomías) como la búsqueda del equilibrio

13 Ibidem, 105.

14 Idem.

15 En este sentido, utilizamos la perspectiva de Lynch $(2004,335)$ sobre las variantes de la modernización en el siglo XVIII español. Lo que, también a nuestro criterio, suponía diversas maneras de pensar la reforma del orden político. 
entre la voluntad regia y los territorios. La primera, más interesada en recuperar de «manera plena» los territorios, se sostenía en la arbitrariedad racional e «iluminista» del monarca; la segunda, en una apelación moral al rey para que limite sus pasiones y se sujete a una constitución que reconozca y articule el poder regio.

La discusión acerca de la reforma de la monarquía presentaba y abría diversos problemas políticos. Entre estos, la reforma que imaginaba Villava colocaba al rey en el lugar de reformador y en una voluntad que podría sujetarse a las leyes que surjan de la misma. Entonces, el monarca como poder no condicionado podía sumir a España y a las Américas en una reformulación (cultural, política, educativa) encaminada a una suerte de monarquía racional y constitucional. Se pensaba en una monarquía en la que el soberano, guiado por su razón y por su comprensión de los espíritus de la época, encontraría conveniente sujetarse a sí mismo a las propias leyes que él había ratificado y que impulsaría en un parlamento.

En términos generales, el fiscal Villava incluye en su reforma una mixtura de principios gubernamentales que garantizarían mayores límites y estabilidad política. Esta propuesta le permitía articular — pensando en las relaciones de poder en la metrópoli- el poderío de la nobleza como cuerpo intermediario entre el rey y la plebe con las decisiones legislativas elaboradas por un Consejo de la Nación donde se distribuirían los poderes de todos los estados (nobleza, clero, llano). Los cuales se seleccionarían bajo las formas de designación republicana (el sorteo). De esta manera, en el Consejo de la Nación se reuniría a estamentos elegidos por sorteo y compondría un lugar donde se encontrarían la voluntad real y los diversos estamentos para la realización de leyes.

Con respecto a América, Villava esbozaba una mirada acerca de la dominación peninsular centrándose en el comportamiento de las autoridades y el despliegue del poder en ese territorio. Para el fiscal, el poder virreinal violentaba las libertades a la manera que lo había indicado Juan Viscardo y Guzmán algunos años antes. Al recorrer esa gramática del orden colonial Villava planteaba que:

Como la América se ha mantenido con el gobierno despótico de los Virreyes, se ha creído que así convenía para tenerla sujeta: sin reflexionar que las causas que facilitaron su conquista, subsisten para facilitar con cualquier gobierno su sujeción; pero cuando no subsistan será el mejor gobierno para perderla como súbdita y como amiga. ${ }^{16}$

16 En Levene, 1946, 114. 
Por esto, proponía: «todas las facultades de los virreyes y hasta sus nombres deberían borrarse del código indiano». ${ }^{17}$ Esta evaluación lo impulsa a plantear una redefinición el lazo imperial: América no debe ser ese territorio a depredar, a saquear sus frutos y a sus habitantes, sino una súbdita amiga. Es decir, la reforma imaginada por Villava implicaba una reconfiguración del pacto imperial en términos atlánticos. ${ }^{18}$ El territorio americano debía ser introducido a la monarquía hispana como territorio decisional, con capacidad de establecer con otros territorios una constitución. Esta propuesta política podría funcionar, no solo como el principio rector de una «monarquía renovada», sino como un límite a la revolución ${ }^{19}$ y al descalabro que podrían introducir la arbitrariedad política. Una «buena constitución» podría desatender y provocar cualquier idea que apele al derecho a la resistencia.

\section{Mariano Moreno. Disertación}

El 13 de agosto de 1802, Mariano Moreno presentaba en la Academia Carolina su Disertación Jurídica sobre el servicio personal de los indios en general y sobre el particular de Yanaconas y Mitaxios. Este documento, que recuperaba el Discurso sobre la Mita escrito en 1793 por Victorián de Villava, se presentaba como la continuación de una contienda jurídica que establecía como preocupaciones centrales la situación de los indígenas y del orden político.

La Disertación discutía con aquellas posiciones que consideraban a los indígenas como siervos y, además, reflexiona acerca de las «motivaciones» que habían condenado a los indígenas a trabajos forzosos. Es decir, motivaciones que estructuraban una forma de ejercer el poder y de concebir el orden político.

Mariano Moreno indicaba que considerar en la práctica a los indios como «siervos por naturaleza» — apelando a la «extravagante» doctrina de Aristóteles-, solo tenía como propósito sustraer la libertad y los derechos a las comunidades indígenas y, por lo tanto, desconocer las cédulas reales de 1542 que prohibían taxativamente sujetar a los indios a servicios forzo-

17 Ibidem, 108.

18 Portillo Valdés, 2009a, 43.

19 Portillo Valdés, 2009b, 313. 
sos. Pero también esta perspectiva aristotélica se oponía a la idea inicial de la conquista, que esperaba construir una comunidad formada solo por católicos donde los indios fueran parte de una común ecclesia ${ }^{20} \mathrm{y}$, por ende, parte de un mismo corpus de derechos y obligaciones. La religión incorporaba a los indios a la polis como católicos, pero también como sujetos de derechos y, finalmente, como súbditos. Por ello, según Moreno, era

malicioso y procedido de codicia infernal y diabólica el pretexto que se ha querido para molestar a los indios y hacerlos esclavos diciendo que son como animales brutos e incapaces de reducirse al gremio y fe de la Iglesia Católica. ${ }^{21}$

Ahora bien, en la dinámica social, los indios del Collasuyo habían sido reducidos al trabajo forzado más allá de las leyes que los reconocían como vasallos de la Corona de Castilla. Y ello se debía a que conquistadores, explotadores de los yacimientos mineros, funcionarios y partidarios de la mita fueron más motivados por la «codicia» y por la voluntad de aumentar la coacción sobre las comunidades que por la construcción de un orden justo.

En la Disertación sostiene:

al paso que el nuevo Mundo ha sido por sus riquezas el objeto de la común codicia, han sido sus naturales el blanco de una general contradicción. Desde el primer descubrimiento de estas Américas empezó la malicia a perseguir a unos hombres, que no tuvieron otro delito, que haber nacido en unas tierras que la naturaleza enriqueció con opulencia. ${ }^{22}$

De esta manera, la codicia se vinculaba a la construcción del orden político. Este «motor de las motivaciones» había configurado los vínculos de obediencia y transformado a los indios en meras cosas, desconociendo memorias jurídicas, derechos naturales y otorgados. Ese afán depredador, según Moreno, había construido las ciudades y sus lazos políticos despojando a los indios de «su nativa libertad». ${ }^{23}$

De esta forma, Mariano Moreno establecía una correspondencia entre servidumbre y codicia y, por tanto, indicaba desde diversos aspectos la destrucción del derecho natural, como los derechos reconocidos por la Corona.

20 Portillo Valdés, 2006, 19.

21 Esta cita del cardenal Talavera (1537) es incorporada por Mariano Moreno en su Disertación $(1911,380)$.

22 Moreno, 1911, 377.

23 Idem. 
La minería aparecía en el documento como la metáfora política de un orden injusto y arbitrario que despojaba a ciertos hombres de su primigenia libertad y del reconocimiento de la Corona. Frente a esto, solo quedaba apelar al soberano para que los partidarios de la mita se ajustasen a la ley. Charcas, como la imaginaba Moreno, no podía ser una gran mina, sino un territorio donde reinara la agricultura, la industria, el comercio y la garantía de ciertos derechos. Es decir, no podía ser tratada como una colonia - donde lo significativo era la extracción de minerales y frutos- sino como un reino o provincia con las mismas atribuciones, libertades y derechos que otros reinos.

En la Disertación, Moreno sugiere que el criterio de utilidad podía poner en cuestión la durabilidad del orden político y erosionar la fidelidad al rey. Las sublevaciones indígenas habían demostrado que ello podía ser una realidad. Por lo tanto, la insurgencia indígena asumía dos interpretaciones: para unos, podía ser entendida como un actor ya derrotado por las armas del rey, lo que confirmaba la dominación metropolitana; y, para otros, como el ejemplo de lo que podía causar un gobierno injusto.

Mariano Moreno, a partir de esta perspectiva, comenzaba a plantear un dilema sobre diversas fuentes de legitimidad de la monarquía en América. Por un lado, una legitimidad que podría lograrse con la articulación de beneficio público y la garantía de derechos y, por otro, una legitimidad basada en el poderío de la Corona misma. En este sentido, la primera expresaba una crítica moral al soberano, recuperando una vieja tradición pactista $^{24}$ que argumentaba que tanto el derecho como el gobierno de monarca caían dentro del campo general de la moral. Esta posición, por el contrario, no desdeñaba el beneficio público, sino todo lo contrario, ya que lo insertaba en un lenguaje que combinaba el cálculo racional — provisto por la economía política - con el humanismo propio de las tradiciones pactistas y de la filosofía moral.

Tanto Villava, como Moreno daban cuenta de las contradicciones que habían abierto las reformas borbónicas. De manera singular, realizan ciertas consideraciones para su modificación. Se introducen en una reflexión sobre el orden y sobre sus posibles reformas.

En ambos casos, la presión de la Corona, la política sobre las comunidades indígenas y la afirmación de las prerrogativas reales suscitaban una discusión sobre la condición de los indios y sobre el orden mismo.

24 Ver Chiaramonte, 1992. 


\section{Crisis monárquica y pasquines: erosión y burla}

El cautiverio del monarca español (1808) provocó un conjunto de tensiones en la metrópoli y en los territorios de ultramar, así como en sus instituciones y estructuras de mando. Ciertos actores altoperuanos (miembros del tribunal, ${ }^{25}$ de la Universidad, ${ }^{26}$ del clero), ${ }^{27}$ aprovechando estas circunstancias, pugnaron para reafirmar la autonomía territorial y regional e instalaron una Junta, oponiéndose a la decisión del presidente de la Audiencia ${ }^{28}$ y del Arzobispado. ${ }^{29}$ Para los revolucionarios, la Junta constituía una respuesta a la incertidumbre y al vacío de poder, así como una instancia legítima para la selección de autoridades. Durante 1809, a las tensiones regionales se sumaron aquellas entre autoridades reales y los miembros del tribunal y de la Universidad. ${ }^{30}$ La consideración como traidores a García Pizarro y a Moxó y Francolí por permitir la circulación de documentos de Joaquina Carlota, ${ }^{31}$ y el rechazo de la injerencia del virrey y del presidente de la Audiencia en las decisiones del claustro de doctores empujó a los partidarios del autogobierno a reasumir el poder político. El 25 de mayo de 1809 se instaló la Junta de La Plata, donde los oidores del tribunal y algunos miembros de la Universidad — como los hermanos Zudáñez- y del clero tuvieron un papel destacado. Tiempo después, el 16 de julio de 1809, estalló el alzamiento en La Paz. Un sector de la élite paceña y militar, con ayuda de los insurgentes de La Plata, instaló una junta bajo la presidencia de Pedro Domingo Murillo. Esta elaboró un plan de gobierno y convocó a la elección de diputados. Si bien ambas experiencias serán derrotadas, todo el año de 1809 estuvo signado por los enfrentamientos políticos y una «guerra» de pasquines que buscaban erosionar a las autoridades reales.

El pasquín es una forma de intervención en la disputa política. Si bien puede encontrarse en estos libelos un texto con cierta densidad política y filosófica para ejercer la denuncia mordaz, también incorporan registros discursivos propios de la tradición satírica, la cual busca burlarse de

25 Entre ellos, Miguel López Andreu.

26 Universidad Mayor, Real y Pontificia San Francisco Xavier de Chuquisaca.

27 Entre ellos, el padre José Antonio Medina.

28 Ramón García de León y Pizarro.

29 Arzobispo Benito Moxó y Francolí.

30 Ver Irurozqui, 2007; Roca, 1998.

31 Reina consorte de Portugal (1775-1830), que no bien fue puesto en cautiverio su hermano Fernando VII reclamó - como miembro de la familia de los Borbones - a través de diversos documentos y gestiones diplomáticas la sujeción de los territorios americanos de la monarquía española. 
poderes y funcionarios. Burlar la liturgia de la obediencia y erosionarla, son sus propósitos más inmediatos. Pero, a su vez, esta forma de intervención política que se produce a través de libelos y opúsculos da cuenta de la existencia de una sociabilidad dispuesta a crear o ampliar una opinión pública.

La circulación de los pasquines se articulaba con los flujos del rumor o de la sospecha social. Ampliaban su eficacia entre aquellos sectores que sabían leer y que estaban atentos a las novedades. Pero el pasquín tenía un propósito inmediato y este era suscitar la adhesión a diversas estrategias políticas. De esta manera, buscaban construir una inteligibilidad, respuesta o llamado de «acción rápida» en momentos de vacío de autoridad política.

En el caso del Alto Perú, los aportes de Vitaliano Torrico Panozo ${ }^{32}$ fueron centrales para el relevamiento y análisis de los pasquines. Estos textos, que circulaban fundamentalmente en las ciudades, buscaron construir una narración de la crisis y presentaron una respuesta al vacío político que se suscitó con el cautiverio del rey.

La captura y represión de estos pasquines por parte de las autoridades expresaba el «poder de la letra impresa $»^{33}$ que ellas mismas otorgaban a estos textos. Por lo tanto, estos fueron considerados ilegales por su contenido, así como por su posible capacidad de establecer críticas y legitimaciones a cursos de acción alternativos.

En un pasquín encontrado por las autoridades en el territorio de la Audiencia de Charcas (1809), que lleva por título Copia de la insinuación que hace la razón y la experiencia, para que sus hijos en las Américas, se comuniquen de unos a otros, y de unos pueblos a otros, se explica:

este riesgo que se hallan las Américas, no solo de caer en manos del Francés, o del Portugués, sino también en las del Inglés, o de la tiranía de alguno de los Virreyes, o Gobernadores; así por la fuerza, violencia, engaño y traición, como porque ya debemos contar por muerto sin sucesión alguna al Señor D. Fernando VII... ${ }^{34}$

Es interesante observar la recreación de ciertos miedos políticos, sobre el «caer» en manos de tiranos. En este sentido, el vacío de poder puede provocar fantasías de disolución, pero también puede pensarse como oportunidad para nuevas tiranías. Por lo tanto, en los pasquines hay un

32 Torrico Panozo, 1997.

33 Darnton, 2008, 23.

34 Archivo Histórico Nacional (AHN), Madrid, 21392, 82, f. 1-2v, Papel anónimo titulado «Copia de la insinuación que hace la razón y la experiencia, para que sus hijos en las Américas, se comuniquen de unos a otros, y de unos pueblos a otros», agosto de 1809. 
llamado a «despertarse» o lo que Demélas llamaba, para analizar el diario de José Santos Vargas, la «metáfora del dormir y del despertarse brutal». ${ }^{35}$

En otro pasquín sin fecha encontrado en Charcas, denominado Reparos al anónimo que se indica, encontramos que «si faltando el Sr. D. Fernando, no quisiese ser Francesa, Portuguesa, o Inglesa, no le queda a la América otro recurso, ni otro término que el de gobernarse por sí misma». ${ }^{36}$ En este se construye una legitimación de las propuestas de autogobierno. En este sentido, en otro pasquín (1809) podemos leer:

La América es de los americanos, como España es de los españoles. Recordad que si los tiranos aparecen gigantes, solo porque sus vasallos siguen de rodillas. De pie y erguidos, a la misma altura llegaremos. Sacudamos el pesado yugo. Si con Túpac fuimos vencidos, fue por falta de unión. Que de la tierra del fuego al Golfo de México se oiga un solo grito: libertad. ${ }^{37}$

La crisis que la ausencia del monarca abrió en el Alto Perú permitiría legitimar la trayectoria autonomista a partir de reflexiones sobre las desdichas de la insurgencia indígena. Si bien el reclamo de «América para los americanos» ${ }^{38}$ apelaba a «desprenderse» de una Península ocupada por el ejército napoleónico, la misma tendría una resonancia muy significativa en los partidarios del autogobierno y, luego, en el republicanismo continental.

Por último, otro pasquín encontrado en 1809 en territorio de Charcas, denominado Aviso a este pueblo y consejo a sus mandones, que también sería enviado al virrey Abascal por intermedio de Vicente Nieto, advertía:

\begin{abstract}
Mandones dejad de mentir y enredar, ya nos entendemos, y el fruto que sacáis es irritarnos más: Cuidad no de vuestra autoridad que expira, sino de vuestras personas, reportaos y dad libertad a este (a vosotros) oprimido Pueblo, para que hable en un público congreso, antes que él con las armas en la mano se la tome. Poned la barba en remojo si no siguen los consejos del Duende Americano. ${ }^{39}$
\end{abstract}

Estos libelos presentan dos actitudes políticas frente a la crisis de la monarquía, las cuales no asumen posiciones antimonárquicas. Una de estas que se fundamenta en el imaginario del autogobierno, el cual suponía

\footnotetext{
35 Demélas, 2007, 111.

36 AHN, Madrid, 21392, 82, f. 3-4v, «Reparos al anónimo que se indica».

37 Transcrito en Torrico Panozo, 1997, 152.

38 Una referencia previa a la esgrimida por la doctrina Monroe.

39 Documento transcrito en Torrico Panozo, 1997, 434.
} 
distintos autogobiernos: el autogobierno frente al mandato del virrey de Perú y de Buenos Aires, el autogobierno frente a los mandatos del presidente de la Audiencia y el autogobierno frente a las disposiciones de la Junta Central de Sevilla. Es decir, una experiencia que aspiraba a instituirse en congreso y dictar sus propias leyes. Por otro lado, se presentaba el intento de usurpación del poder del rey por parte de los funcionarios.

En el último pasquín, como advertimos, se realiza una apelación a la conformación de un Congreso donde el pueblo o la comunidad tomen la palabra para establecer respuestas a la crisis y propuestas para la organización del poder político. Y si eso no ocurriese, el autor anónimo advierte que para garantizar dicho derecho se podrían tomar las armas. De este modo, el derecho a la autonomía seria garantizado, como luego sucedió, con el poder de las armas.

Los pasquines, de esta manera, van construyendo un haz de argumentos y propuestas que están orientadas a legitimar el autogobierno. También ofrecen una «escenografía del campo político», es decir, dividen el campo entre amigos-enemigos y, por ende, entre propuestas y acciones antagónicas.

\section{Carta Pastoral e intervención de Benito Moxó y Francolí}

El estudio de Marta Irurozqui ${ }^{40}$ sobre los sermones y catecismos políticos nos habla de la capacidad de los miembros del clero de intervenir en la crisis monárquica. Demuestra la capacidad de estos sermones y catecismos de recrear posiciones e interpretaciones sobre los hechos y de suscitar una acción determinada. Los sermones son «textos de combate», pero también de convocatoria a recrearlos.

El arzobispo Moxó y Francolí, como otros tantos letrados, va a intervenir en una polémica sobre la sustancia misma del poder y de la política. $\mathrm{Su}$ enfrentamiento con las experiencias juntistas de La Plata (1809) y La Paz (1809) queda de manifiesto en su Carta Pastoral indicando que los actores sociales debían renunciar a toda capacidad de ejercicio soberano. Lo interesante de este planteo, es que el 9 de enero de 1809 este eclesiástico había llamado a obedecer a la Junta Central metropolitana y, pese a que la misma fundamentaba su establecimiento en la soberanía de las juntas

40 Irurozqui, 2002. 
provinciales, advertía que ese órgano colegiado lo «acabamos de recibir del Dios de nuestros padres».41

Entre la derrota de las experiencias juntistas de 1809 en el Alto Perú y el retomado control de ese territorio por las fuerzas del virrey Abascal, Moxó y Francolí volvía a reivindicar el argumento regalista. La recuperación del control territorial por parte del virrey del Perú en 1810, posibilita que el arzobispo reivindique la capacidad del regalismo para suscitar adhesiones y afirmar una concepción del orden político.

Moxó y Francolí consideraba que la autoridad no es el resultado de la voluntad de la comunidad, sino que

la autoridad de mando a los pueblos, no es, como se imaginan los libertinos, una invención puramente humana, o un efecto de la ambición y violencia de los poderosos; sino al contrario una verdadera emanación de la suprema autoridad de Dios. ${ }^{42}$

De esta forma, Dios se constituye en la fuente del mando, pero a su vez se erige como aquella figura que «ha mandado, que a imitación de los que navegan, uno tenga a su cargo el timón y los demás obedezcan y cumplan sus órdenes». ${ }^{43}$ Es decir, Dios se volvía una metáfora del dominio político y del ejercicio del poder.

La reivindicación de Dios como fuente de poder impugnaba todas las tradiciones pactistas - tanto la elaborada por la Escuela de Salamanca como las presentadas por Grocio, Puferndorf, Vattel, etc.— y a su vez introducía la asociación entre el pactismo y lo amoral. En este sentido, el arzobispo, ante la ausencia de Fernando VII, reactualizaba la idea de que a la monarquía le corresponde una moral, es decir, la «única» moral política. De esta manera, la crisis de la autoridad monárquica lo impulsaba a reivindicar la idea de un orden $-\mathrm{y}$ no ya de una figura - sujeto a una moral del poder.

La otra particularidad del razonamiento de Moxó y Francolí, es que en su negación de cualquier idea que impute a la comunidad la fuente de soberanía, objetaba directamente al pactismo de origen católico que tanta

41 Archivo y Biblioteca Nacionales de Bolivia (ABNB), Sucre, M588 166-183, «Homilía que pronunció el 9 de enero de 1809 el Ilustrísimo Señor Don Benito María de Moxó y Francolí. Juramento de obediencia a la Suprema Junta Central», La Plata, 9 de enero de 1809.

42 Archivo General de la Nación (AGN), Buenos Aires, BM-1966, «Benito María de Moxó y de Francolí. Carta Pastoral del Ilmo. Sr. Arzobispo de La Plata, sobre la obediencia y sumisión que se debe a las potestades legítimas. Real Imprenta de los niños expósitos», Buenos Aires, 22 de febrero de 1810.

43 Idem. 
prédica había tenido en Europa y en la península Ibérica durante los años de la Contrarreforma.

En este sentido, la Carta Pastoral venía a discutir con los partidarios de la reasunción de los derechos del rey y principalmente contra las élites que habían dirigido los procesos autonomistas de La Plata y La Paz. Estas habían colocado a la ciudad como fuente de soberanía, trastocando el fundamento regalista y abriendo una polémica sobre el «origen y legitimidad» de la autoridad.

Moxó y Francolí entendía que los sucesos de La Plata y de La Paz fueron intentos por trastocar el poder y sus seguridades. Por ello, pretende que el «Pueblo», constituido por los insurgentes como el locus de la soberanía, debía regresar a su antigua dominación y sustraerse de cualquier concepción «libertina», la cual solo creaba «fantasías monstruosas» entre las personas. Estas solo debían orar «a Dios por la salud y prosperidad de los Monarcas, deseándoles una vida larga, un imperio quieto, un palacio tranquilo y seguro, unos ejércitos fuertes, un Senado fiel, un pueblo dócil y bueno, el universo sumiso y pacato». ${ }^{44}$ Por tanto, el prelado asumía un gran desafío porque, al igual que lo que había ocurrido durante la insurgencia indígena (1780-83), el regalismo se encontraba nuevamente ante la necesidad de disputar en los diversos estratos sociales su propia legitimidad y ajustar cuentas con el imaginario autonomista.

La estrategia pedagógica utilizada por Moxó y Francolí fue buscar entre los pasajes bíblicos aquellos que podían asociarse a los tiempos convulsionados de su presente. Para esto, el autor comparó «el pueblo» de la Biblia con «el pueblo» de Charcas y así relacionó algunas de sus reflexiones con los sucesos ocurridos en el Alto Perú. La impugnación no solo se dirigía a los dirigentes sino a toda la comunidad y a sus posibles imaginaciones, dando cuenta de lo que había implicado el proceso de autogobierno. Hablando del «pueblo de la Biblia», advertía que «nunca se les oía a aquellos sencillos discípulos murmurar del gobierno, o hablar con desprecio de las autoridades constituidas, fuesen las que fuesen». Y en otro párrafo aseguraba que «censurar y calumniar a los Jefes, se ha mirado en todos los siglos y en todas las Naciones como prueba de un carácter funesto a la patria» ${ }^{45}$ En este sentido, despreciar y calumniar a las autoridades no solo era atentar contra Dios sino contra la patria misma.

44 Idem.

45 Idem. 
El lenguaje regalista que vinculaba Dios, rey y patria ${ }^{46}$ contaba con una fundamentación religiosa que, paradójicamente, eran las mismas fuentes teológicas que habían justificado el luteranismo para iniciar el cisma en el mundo católico. La prédica paulista ${ }^{47}$ era un recurso que católicos y protestantes utilizaron para fundamentar el orden establecido.

Ante la crisis y la disputa de 1809, según la Carta Pastoral, la religión podía superar las divisiones, conducir a los hombres a aceptar la voluntad del rey y de sus funcionarios y clausurar esa voluntad que empujaba a los hombres a que «se envistan y despedacen mutuamente, como los tigres y los osos de los montes» ${ }^{48}$ De esta manera, el cuerpo moral y ético de la religión podía asumir su objetivo: religar a los hombres entre sí y conducirlos al orden anterior.

Para el arzobispo, «obedecer y callar es y ha sido siempre la divisa de un cristiano y de un Ciudadano de Honor» ${ }^{49}$ Así, el prelado construía un relato sobre el buen ciudadano cristiano, aquel que debía aceptar resignadamente las decisiones del monarca y sus representantes. De esta manera, reivindicaba la fórmula de dominación regalista: vasallo de Dios y vasallo del rey, a la manera de un entramado indisociable e inherente.

La efectividad de la prédica paulista tendría sus efectos, inclusive, dilemáticos. De hecho, algunos acusados de dar su apoyo a Juan José Castelli ${ }^{50}$ - luego de su derrota en Huaqui (1811) y posterior retiradafundamentaron su adhesión a través del recurso paulista. En el Expediente formado en virtud de la causa criminal seguida contra el Abogado Don Manuel Eusebio Ruiz por haber sentado en un Escrito de que la autoridad de Castelli fue legítima (1812) se indicaba que el acusado había esgrimido que su apoyo al jefe del Ejército Auxiliador del Alto Perú se debía a que

46 Sobre esta relación ver Elliott, 2004.

47 Nos referimos a la posición del apóstol san Pablo en Romanos, XIII, 1-3. Aquí indica: «Todos deben estar sometidos a las autoridades superiores, pues no hay autoridad sino bajo Dios; y las que hay, por Dios han sido establecidas, de suerte que quien resiste la autoridad, resiste a la disposición de Dios».

48 AGN, Buenos Aires, BM-1966, «Benito María de Moxó y de Francolí. Carta Pastoral del Ilmo. Sr. Arzobispo de La Plata, sobre la obediencia y sumisión que se debe a las potestades legítimas. Real Imprenta de los niños expósitos», Buenos Aires, 22 de febrero de 1810.

49 Idem.

50 La junta revolucionaria de Buenos Aires lo nombró jefe del Ejército Expedicionario (9 de junio de 1810) y dirigió la primera expedición auxiliadora al Alto Perú. Fusiló en Córdoba al ex-virrey Santiago de Liniers por conspirar contra el nuevo gobierno y entre septiembre y noviembre de 1810 tomó el control del Alto Perú. Ante la derrota infringida por el ejército realista de Juan Manuel de Goyeneche en Huaqui, Castelli abandonó el Alto Perú. 


\section{ESTEBAN DE GORI}

de los principios de una sana filosofía, y de los preceptos de nuestra religión cristiana: siguiendo al Apóstol San Pablo en la epístola trece a los Romanos, que dice, que no hay potestad que no venga de Dios, y así todas las que hay son ordenadas por Dios, Por lo tanto, quien resiste a la potestad resiste a las órdenes de Dios, y por eso es necesario estar obediente a cualquiera autoridades, no solo por temor de la fuerza, sino también por la conciencia. ${ }^{51}$

De alguna manera, podemos observar cómo el «recurso paulista» - tan reivindicado por el regalismo- había servido como un argumento legitimador para explicar la obediencia a las autoridades revolucionarias.

Este Expediente concluía con una más que interesante resolución, ya que el agente letrado que oficiaba de fiscal entendió que dicha apelación era subversiva y sediciosa. Allí se indicaba que

la proposición de que Castelli y sus socios fueron potestades de las que habla el Apóstol, con obligación a obedecerlos de parte nuestra, y que [...] se sometió porque el evangelio nos lo manda, es tan aventurada, sacrílega, y escandalosa, que faltaría a su deber de fiscal si no la denunciase, como la más sediciosa, y subversiva.

En este caso, el recurso paulista solo podría ser utilizado por los funcionarios borbónicos, desacoplándolo de cualquier otra apelación a la subordinación de otra autoridad.

Entonces, podemos observar cómo la lucha interpretativa por la fundamentación de las acciones era utilizada y era reapropiada por diversos actores, inclusive observamos cómo el «recurso paulista» se instrumentalizó para legitimar su adhesión a las órdenes de Castelli.

\section{Matías Terrazas: constitucionalismo y regalismo}

Matías Terrazas pertenecía a la élite eclesiástica. Posee una historia política singular durante los acontecimientos que se suscitan durante la crisis monárquica en el Alto Perú. Como profesor de la Universidad San Francisco Xavier de Chuquisaca ${ }^{52}$ firmó en 1809 la denominada Acta de los Doctores..$^{53}$ Este documento se oponía a la pretensión de la corte de

51 ABNB, Sucre, Em. 121, «Expediente formado en virtud de la causa criminal seguida contra el Abogado Don Manuel Eusebio Ruiz por haber sentado en un Escrito de que la autoridad de Castelli fue legítima», La Plata, 9 de octubre de 1812.

52 Ver Thibaud, 2010.

53 Ver Irurozqui, 2007. 
Portugal (residente en Brasil) de reclamar los territorios del Alto Perú y reafirmaba la obediencia al cautivo rey Fernando VII. A su vez, mandaba a las autoridades reales retirar los documentos enviados por Carlota Joaquina $^{54}$ y censuraba cualquier tipo de vínculo con esta. Por lo tanto, si bien los firmantes reivindicaban la dominación de Fernando VII, abrían al mismo tiempo una confrontación con las autoridades virreinales. Estas, según el tribunal y el claustro universitario, habían mantenido una relación ambigua con respecto a las proposiciones portuguesas. Por lo tanto, se las culpaba de haber hecho públicas las reclamaciones de Carlota Joaquina e inclusive de sentirse «seducidos» por las mismas.

Matías Terrazas fue parte de aquellos hombres de saber que habían colaborado con la configuración de espacios de sociabilidad entre el claustro universitario y los tribunales. A su vez, es importante considerar otro dato político: durante 1809, Terrazas no legitimó las posiciones adoptadas por el arzobispo Moxó y Francolí, las cuales adherían a la autoridad del presidente de la Audiencia. Por lo tanto, asumió en su práctica política dos pertenencias: al clero y a la sociabilidad construida en relación a la universidad.

A diferencia del regalismo de Moxó y Francolí, Matías Terrazas apoyará la propuesta constitucional gaditana, por lo menos, hasta que la guerra haya exacerbado la construcción de bandos irreconciliables. En 1813, el deán en su Exhortación ${ }^{55}$ del 6 de enero convertirá su discurso y a la Iglesia misma de la ciudad de La Plata en estrategias de legitimación de la Constitución elaborada en Cádiz en $1812 .{ }^{56}$ Esta, según su mirada, era el resultado de una fórmula política que aseguraba el trono pero que al mismo tiempo reconocía y legitimaba la capacidad constituyente de los pueblos y reinos. Las cortes habían introducido en esta fórmula constitucional al rey y lo habían sometido a los límites que la Constitución implicaba. De esta manera, el regalismo quedaba desterrado de su discursividad.

54 Ver nota 31.

55 ABNB, Sucre E-123, «Exhortación hecha en la Catedral de la Ciudad de La Plata por el Señor Doctor Don Matías Terrazas, Deán de dicha Santa Iglesia, el día de la publicación y jura de la Constitución Política de la Monarquía Española», La Plata, 6 de enero de 1813.

56 La Constitución de Cádiz de 1812 determinaba como forma de gobierno la monarquía constitucional. Este texto proponía una organización centralista de todos los territorios de la monarquía, establecía ayuntamientos constitucionales y la elección de diputaciones provinciales pero ambas instituciones eran limitadas por un jefe político nombrado por la metrópoli. Con esto se buscaba reconstruir el resquebrajado orbe imperial y, fundamentalmente, clausurar las experiencias juntistas. 
Con respecto a la Constitución gaditana, Terrazas indicaba:

Veo en este majestuoso aparato a una de las más respetables poblaciones de la América meridional: a la muy noble, leal y valerosa ciudad de La Plata, a ese pueblo religioso, ilustrado, magnánimo, siempre fiel a su nación, siempre leal a su legítimo soberano; lo veo, digo, pronto a jurar y obedecer las sanciones de un código sagrado, que ha sido y será perpetuamente la admiración de todo el mundo, y la gloria de la nación española. De un código que en sus cláusulas respira piedad para con Dios, fidelidad para con el soberano, amor para con los ciudadanos, interés por el bien de la nación, celo por la observancia de las leyes. ${ }^{57}$

En su Exhortación recurre - como lo vimos en los textos de Moxó y Francolí- a las comparaciones entre la Biblia y los sucesos gaditanos, haciendo del lenguaje político una didáctica de la legitimación. Cádiz era comparada con el monte Sinaí y la constitución se homologaba a las Tablas de la Ley presentadas por Moisés a su pueblo. Es decir, a partir del texto bíblico los letrados católicos construyeron una historia política común entre el texto bíblico y el mundo ibérico. ${ }^{58}$ El pueblo español caminaba sobre las mismas huellas que el pueblo de Moisés. La metáfora de Sinaí poseía una significación política relevante, ya que es el lugar del pacto entre el pueblo hebreo y Dios. De esta manera, la metáfora venía a reafirmar ese pacto que se había reconocido en Cádiz entre el rey y los pueblos. Entonces, tanto el Sinaí como Cádiz se tornaban metáforas del pacto y del surgimiento de una nueva ley.

La iglesia de la ciudad de La Plata fue transformada por Terrazas, como lo fue el Sinaí, en el lugar donde se dio lectura a las leyes y se convocó al pueblo a obedecerlas. Por una suerte de transposición la Iglesia asumía el lugar de Moisés. Es decir, aquella institución que traía y mostraba la ley a su comunidad. Según del deán Terrazas,

la Constitución que sale de sus manos reconoce un gobierno monárquico, dulce, justo, útil, amable, y por lo mismo más prudente en lo que cabe entre las vicisitudes humanas. En él se establece el pacto social más religioso y equitativo entre el rey y los vasallos. En él se deslindan con la mayor claridad los sagrados derechos del monarca, y los fueros propios de la nación. [...] Se establece un sistema de monarquía, propia, equitativa, paterna, templada, que pone a cubierto al monarca y a los vasallos, de los terribles estragos, o de la anarquía o del despotismo. ${ }^{59}$

57 Ver nota 55.

58 Esta relación no es novedosa, como tampoco lo es la apelación a los mandatos bíblicos. En este sentido debemos recordar que la conquista de América se vinculó a un plan de Dios.

59 Ver nota 55. 
La Constitución gaditana, en palabras de Terrazas, venía a reconocer ambos derechos: el derecho regio y los derechos de los pueblos. Pero sobre todo, venía a plantear que sus preceptos ponían a cubierto al monarca y a los pueblos, estableciendo límites y garantías. Ahora existía una ley que limitaría el despotismo y la anarquía. En este sentido, se planteaba en la Exhortación:

Españoles generosos, americanos ilustres, fieles chuquisaqueños: se nos presenta la gran Constitución política de la nación española; jurémosla, obedezcámosla, besémosla, estrechémosla entre nuestros pechos, pongámosla sobre nuestras cabezas. ${ }^{60}$

Por tanto, esta Constitución debía ser obedecida por los hombres y pueblos a ambos lados del Atlántico. La misma intentaba restablecer un imperio (político) que comenzaba a resquebrajarse. Es decir, la Constitución podía presentarse como una estrategia para fortalecer la novísima monarquía constitucional y así clausurar la imagen de un mundo hispano en ruinas. En este sentido, los hombres debían aceptarla ya que sería, según Terrazas, «el principio de la regeneración del reino», «el cimiento solido del glorioso trono de nuestros monarcas», «el apoyo de la justa y reglada libertad de los ciudadanos, y últimamente como la fuente y el origen de la felicidad de las Américas». ${ }^{61}$ A su vez, la Constitución podía establecerse como una posibilidad para cerrar el proceso revolucionario iniciado en Charcas y seguido por la élite revolucionaria rioplatense que instaló en 1810 la Junta Provisoria de Buenos Aires.

Una dimensión interesante a destacar de Terrazas es que su apelación a la obediencia se construye nuevamente a través de las palabras de san Pablo. El «recurso paulista» se torna eficaz para lograr la subordinación, no ya a un rey que no retorna, sino a una constitución que busca reconstruir una soberanía política. Si bien las reflexiones de san Pablo aparecían, en la carta de Moxó y Francolí, como la mejor fundamentación para la sujeción a los príncipes, en la Exhortación de Matías Terrazas aparecerían como la mejor fundamentación para apelar a la obediencia hacia las cortes y al cuerpo constitucional. Por ello, se preguntaba: «ipodrá haber autoridad mas legítima que las de unas Cortes que representan toda la nación?». De esta forma, las cortes se transformaban en una suerte de Príncipe colegiado, y el rey en una autoridad que «suscribiría gustoso a unas decisiones que

60 Idem.

61 Idem. 
sin perjudicar sustancialmente los sagrados derechos de majestad, precaven en lo posible los abusos que la vil adulación...». ${ }^{62}$

Esta fórmula constitucional tenía como propósito superar las pugnas y los enfrentamientos y solo la obediencia a la Constitución impediría que «nos separásemos de su generoso modo de pensar, y no despedazásemos en cismas y guerras civiles» ${ }^{63}$ Por tanto, la Constitución asumía otra significación lexical, la constitución como «conjuro» a la guerra civil.

La Exhortación recogía una propuesta reformista, inclusive ya planteada por Victorián de Villava (1797), donde afirmaba: «Sí, Americanos ilustres: tendréis parte en el cuerpo legislativo: vuestros diputados, [...] tendrán el voto para sancionar las leyes en las Cortes». ${ }^{64}$

En el lenguaje de Matías Terrazas, a la luz de los acontecimientos en 1813, podemos observar la recreación del imaginario pactista y constitucionalista. La reactualización de las esperanzas regeneracionistas y reformistas del reino y la afirmación, ineludible, de que la «Nación» - como sujeto en el cual residía la soberanía - se había transformado en el protagonista de los debates constitucionales en Cádiz. Entonces, no solo se advertía una reformulación del vocablo nación, antes relacionado a lo territorial y local, sino que esta nueva significación permitía apelar a una soberanía indivisible y unitaria ${ }^{65}$ que discipline a los actores y pueblos. Pero, a su vez, debemos considerar que su construcción discursiva, si bien reafirmaba la cultura pactista, incorporaba la afirmación del rey como lugarteniente de Dios. Pero ya no un vicario de Dios, como defendían los partidarios del derecho divino, sino un lugarteniente limitado por otra fuente de autoridad: las cortes. Estas contradicciones daban cuenta de la dinámica política y de las representaciones de los actores en dicha dinámica. De esta forma, esta discursividad mantenía una cohabitación de imaginarios, de manera tal que no lesionaba la voluntad regia y la voluntad de la nación.

En junio de 1813, el Ejército del Norte al mando de Manuel Belgrano toma el control sobre el Alto Perú y es derrotado por las fuerzas militares del virrey del Perú en noviembre de dicho año. Esta trágica situación no le impidió buscar nuevos aliados y continuar fortaleciendo las guerrillas altoperuanas. En enero de dicho año se había inaugurado en Buenos Aires la Asamblea del Año XIII, intentando construir un orden político y territorial
62 Idem.
63 Idem.
64 Idem.
65 Ternavasio, 2009, 87 
estable y teniendo como propósito establecer una Constitución autónoma con respecto a la elaborada en Cádiz.

Mientras se mantuvo el control del ejército de Belgrano, fue aceptada la soberanía de la Asamblea Constituyente. En un Oficio ${ }^{66}$ del Dr. Esteban Gazcon $^{67}$ se manifestaba la decisión y necesidad del general en jefe del Ejército Auxiliar de lograr el reconocimiento de la Asamblea como autoridad soberana. Para ello, se establecía una fecha para su reconocimiento y se abría un proceso de selección de diputados, intentando ampliar la «composición territorial y representacional». Pero el juramento no sería realizado por la derrota de las fuerzas el Belgrano.

Un mes después de la misma, Matías Terraza escribía un sermón que hacía referencia a la experiencia de autogobierno rioplatense y a la convocatoria de la Asamblea General Constituyente. Ante estos sucesos políticos, las autoridades reales que habían retomado el control sobre Charcas van a afirmar la narración de un conflicto atravesado por propuestas irreconciliables. En esta coyuntura, se va forjando el bando realista; bando enfrentado a secesionistas o autonomistas. Es decir, el bando del rey construye su identidad en relación al apoyo que ejércitos y élites dispensan al monarca cautivo y a las decisiones políticas peninsulares.

La consolidación del virrey Abascal en territorios altoperuanos hizo que Matías Terrazas apoyara a su ejército y elaborara una discursividad donde se indicará cómo la religión y el mismísimo Dios intervienen en el bando del rey. En el conflicto bélico entre Pezuela (jefe de los ejércitos del virrey Abascal) y los partidarios del autogobierno; Dios, la Virgen María y la Virgen del Carmen son «sumados» al bando del rey.

Para indagar sobre este Sermón es interesante considerar la realidad política y los actores gravitantes en Charcas. Y esto lo advertimos porque en este texto Matías Terrazas no se refiere a la Constitución de Cádiz, sino que reafirmará la voluntad del rey, a quien se «debe honrar con sumisión y fidelidad». ${ }^{68}$

66 ABNB, Sucre, Em. 145, «Oficio del Dr. Esteban Gazcón a los Ministros de Hacienda pública de las Cajas principales: transcribe la superior orden sobre la jura y reconocimiento de la Soberana Asamblea general constituyente instalada en la Capital de Buenos Aires», La Plata, 28 de junio de 1813 .

67 Participó en la revolución de La Plata en 1809. Fue nombrado presidente de la Real Audiencia de Charcas por Juan José Castelli, y luego es restituido por Belgrano como presidente de la Audiencia y, a su vez, elegido como gobernador de Charcas. Después de la derrota en Ayohuma (1813) se puso a las órdenes del gobierno de Buenos Aires.

68 Ver nota 66. 
Terrazas se pliega al avance de Pezuela y se incorpora a su estrategia política. El imaginario pactista y constitucionalista da lugar a la reivindicación de las prerrogativas de la Corona. Es decir, el argumento «pactista»se destruye con la guerra («ya no hay pacto, hay guerra»), pero también esto se produce por la decisión del virrey Abascal de no defender la Constitución gaditana.

En su Sermón se pronunciará contra el establecimiento de la Asamblea en el Río de la Plata, ya que este cuerpo colegiado era considerado como un actor que disputaba la soberanía del rey y, a su vez, que pondría en duda la religión.

En este contexto, donde el poder militar y político de Pezuela presiona sobre los demás actores, Terrazas vuelve a las fórmulas regalistas, advirtiendo que «Dios es el principio y forma del origen de la autoridad de los Reyes». ${ }^{69}$ En este sentido, indica que:

en efecto, señores la religión misma es la que nos impone esta obligación, este deber capital del amor, del respeto, de la obediencia debida al Monarca [...] Una Monarquía florece, disfruta las dulzuras de la paz, y de todas las ventajas de la abundancia, mientras conserva la sumisión á su legítimo Rey. Por el contrario, si quiere romper el freno de la obediencia, ella por sí misma se acarrea incalculables desgracias, y viene á ser víctima de su propio desorden. ${ }^{70}$

En el Sermón impugna al proceso juntista iniciado en Buenos Aires, manifestando que este había soslayado la voluntad absoluta del rey. El signo demostrativo de ello residía en que en el correr del tiempo la Junta de Buenos Aires «abroquelándose con el sagrado nombre del Monarca, toma las riendas del gobierno». De esta forma, según Terrazas, «los lobos se disfrazan con la piel de las ovejas; con el mismo real manto de Fernando quiere encubrirse la infamia de la rebelión». ${ }^{11}$ La apelación al nombre del rey sería considerada por el poder revolucionario como una simulación para realizar sus proyectos. En este sentido indica: «los lobos aparecen en sus propias pieles, se erige la pretendida soberanía de las Provincias unidas del Río de la Plata; y para representarla se instala una asamblea en la Capital de Buenos-Ayres». ${ }^{72}$ Terrazas, comprendiendo que Charcas es un territorio en disputa, al plantear que la Junta de Buenos Aires simula su
69 Idem.
70 Idem.
71 Idem.
72 Idem. 
adhesión al rey, introduce esta clave explicativa para deslegitimar al proceso autonomista.

En este lenguaje de la sospecha busca instalar una imagen de los juntistas rioplatenses e indicar que se habían apropiado de una soberanía que no les pertenecía porque el rey no ha muerto. Por lo tanto el Sermón, a su vez, busca restituir la imagen de un rey vivo y con capacidades futuras de mando. Entonces, el planteo de que el monarca no podría gobernar en el futuro se volvía un desacato al poder regio y divino. Por ello, Terrazas se pregunta: «¿Quién sois vosotros que de ese modo queréis tentar a Dios y poner límites a su poder?». ${ }^{73}$ El regalismo de Terrazas vuelve a buscar los fundamentos en la doctrina del derecho divino para deslegitimar las acciones de los partidarios del autogobierno y vuelve a reactualizar los debates que se suscitaron en las disputas entre el presidente de la Audiencia y los jueces del tribunal durante 1809 en La Plata. Con la fuerza militar y política de Pezuela, Terrazas busca otro «cierre o clausura» del ciclo de la crisis distinto al constitucional. Por ello, indicará que

en la debida subordinación al rey, y á las Autoridades legítimas que gobiernan á su nombre, consiste la verdadera felicidad de la América, y no en las ilusiones de una independencia y libertad ilimitada, quimérica, y mal entendida. ${ }^{74}$

La propuesta de Terrazas es resignificada bajo la perspectiva del derecho divino de los reyes. De esta forma, daba por tierra sus anteriores apelaciones a la fórmula constitucional y sustraía cualquier capacidad instituyente de la comunidad. La estrategia política de Pezuela, compartida en este contexto por Terrazas, pretendía negar esos derechos de transmisión de la soberanía por parte de la comunidad y reafirmar la sujeción inevitable al rey y a sus autoridades.

La radicalización de la guerra y el control de Charcas por el virrey de Perú había impulsado a letrados como Terrazas a desplazarse de un registro político a otro y habían permitido la construcción de un escenario discursivo irreconciliable donde los partidarios de la metrópoli se negaban, ya sea por la desconfianza de algunos funcionarios en la Constitución de Cádiz o por el «peligro» que suponían en la metáfora pactista, a reconocer cualquier planteo que imputase a la comunidad cierta capacidad soberana.

73 Idem.

74 Idem. 


\section{Consideraciones finales}

Las contiendas políticas que se produjeron durante el período que se extiende desde las reformas borbónicas hasta la instalación de la Asamblea del Año XIII supusieron la reactualización de imaginarios políticos que habitan el universo de la monarquía hispana para fundamentar las acciones de los actores, así como las diversas respuestas a las crisis abiertas por las reformas borbónicas y por el cautiverio del rey. Encontramos vocabularios, lenguajes e imaginarios que orientaron a los hombres en dichas acciones, o a actores que en su intervención los «colocan en escena» para suscitar la acción de los agentes. Los hombres de saber, a través de sus «textos de combate», no solo dieron cuenta de la posición que poseían en las diversas polémicas, sino que se tornaron indispensables para la disputa representacional e imaginaria. Ellos, intentando animar la discusión y la polémica, establecieron marcos interpretativos sobre conflictos y tensiones.

Ahora bien, si consideramos desde una perspectiva de largo alcance las reflexiones reformistas de Victorián de Villava hasta la defensa regalista de Terrazas en su Sermón; podemos sugerir que el intento por clausurar el conflicto político abierto con la crisis de 1808 llevó a las autoridades virreinales a esgrimir distintas estrategias políticas y discursivas para mantener, relegitimar y reformular — sobre todo en 1812 con la Constitución de Cádiz- el dominio político e imperial. El «imperio de lo político y del dominio» fueron las grandes preocupaciones de los metropolitanos y sus partidarios americanos. Si bien estas estrategias se hacían cargo de los conflictos iniciados con las reformas borbónicas y de los vaivenes de la guerra, habían soslayado la intensidad disruptiva que causa el vacío de autoridad y la acción de las élites autonomistas.

$\mathrm{Al}$ considerar cada una de las propuestas y trayectorias discursivas podemos advertir cómo a partir de diversas coyunturas se fueron disponiendo, enfrentando y cohabitando distintos imaginarios y vocabularios políticos. Imaginarios que, debemos decir, se fueron desplegando con diversas intensidades y adhesiones en el periodo que se extiende de las reformas borbónicas hasta la propuesta constitucional del Año XIII.

El cisma fundamental en el universo de los imaginarios se produce ante la ausencia del rey y, por ende, de su presencia legitimadora de las instituciones y autoridades. Esta ausencia abrió una disputa entre los actores políticos acerca de si los pueblos y ciudades poseían el derecho o no a constituirse en sujetos transmisores de soberanía. Entonces, la apropiación 
de la tradición que fundamentaba el derecho a transmitir soberanía empujó a los partidarios del autogobierno al enfrentamiento con las autoridades virreinales. Estas últimas se apropiaron de todas aquellas representaciones y discursividades que les permitían retener, recuperar o ampliar su poder. La apelación al derecho divino, la asociación de lenguajes bíblicos con los sucesos políticos peninsulares, el apoyo a la Constitución de Cádiz, así como el «recurso paulista», fueron todos usos posibles para clausurar los peligros disolutorios del orden que supusieron la ausencia radical del rey, el vacío y la incertidumbre. En la pugna entre imaginarios pactistas y regalistas, existió una «variedad» de posiciones, desplazamientos, yuxtaposiciones, «grises» y dicotomías. Todos estos usos fueron articulados en las condiciones de posibilidad simbólica que planteaba la dinámica política.

Los actores políticos del territorio de Charcas forjaron mutaciones, variaciones y resignificaciones de sus proyectos y los hombres de saber no estuvieron exentos de la intensidad y «toma de posición» que suponía la intervención política. Las tensiones que abrieron las reformas borbónicas, la crisis monárquica, el enfrentamiento bélico, el control territorial ejercido por uno y otro bando, forjaron un escenario de discursividades e imaginarios que develaron la complejidad misma de un proceso atravesado por las contingencias de las pugnas políticas.

Recibido el 1 de julio de 2014

Aceptado 19 de marzo de 2015

\section{Bibliografía}

Baczko, B.: Los imaginarios sociales. Memorias y esperanzas colectivas, Buenos Aires, Nueva Visión, 1999.

Chiaramonte, J. C.: La crítica ilustrada de la realidad: economía y sociedad en el pensamiento argentino e hispanoamericano del siglo XVIII, Buenos Aires, CEAL, 1992.

Darnton, R.: Los best sellers prohibidos en Francia antes de la revolución, Buenos Aires, FCE, 2008.

Demélas, M.: Nacimiento de la guerra de guerrilla. El diario de José Santos Vargas (1814-1825), Bolivia, Instituto Francés de Estudios Andinos, Plural, 2007.

Elliott, J.: «Rey y patria en el mundo hispánico», en Mínguez, V. y Chust, M. (eds.), El imperio sublevado. Monarquía y Naciones en España e Hispanoamérica, Madrid, CSIC, 2004, 17-36. 
Fernández Sebastián, J. (dir.): Diccionario político y social del mundo iberoamericano. La era de las revoluciones 1750-1850, Madrid, Fundación Carolina, Sociedad Estatal de Conmemoraciones Culturales, Centro de Estudios Políticos y Constitucionales, 2009.

Fradkin, R. y Garavaglia, J. C.: La Argentina colonial. El Río de la Plata entre los siglos XVI y XIX, Buenos Aires, Siglo Veintiuno Editores, 2009.

Irurozqui, M.: «El sueño del ciudadano. Sermones y Catecismos políticos en Charcas tardocolonial», en Quijada, M. y Bustamante, J., Élites intelectuales y modelos colectivos. Mundo Ibérico (Siglo XVI-XIX), Madrid, CSIC, 2002, 219-250.

Irurozqui, M.: «Del Acta de los Doctores al Plan de Gobierno: Las juntas en la Audiencia de Charcas (1808-1810)», en Chust, M. (coord.), 1808: la eclosión juntera en el mundo hispano, México, FCE, 2007, 192-226.

Levene, R.: Vida y escritos de Victorián de Villava, Buenos Aires, Peuser, 1946.

Lynch, J.: La España del siglo XVIII, Madrid, Crítica, 2004.

Myers, J.: «Los intelectuales latinoamericanos desde la colonia hasta el inicio del siglo XX», en Altamirano, C. (dir.), Historia de los intelectuales en América Latina. Tomo I. La ciudad letrada, de la conquista el modernismo, Buenos Aires, Katz, 2008, 121-144.

Mazín, O.: «Gente de saber en los virreinatos de Hispanoamérica (siglos XVI a XVIII)», en Carlos Altamirano (dir.), Historia de los intelectuales en América Latina. Tomo I, Madrid, Katz, 2008, 53-78.

Moreno, M.: «Disertación Jurídica sobre el servicio personal de los indios en general y en particular de Yanaconas y Mitaxios» [1802], Revista de Derecho, Historia y Letras, T. XXXVIII, Buenos Aires, 1911, 377-391 y 582-594.

O'Phelan Godoy, S.: La gran rebelión de los Andes: de Túpac Amaru a Túpac Catari, Cusco, CBC, Petroperú, 1995.

Portillo Valdés, J. M.: Crisis atlántica. Autonomía e independencia en la crisis de la monarquía hispana, Madrid, Fundación Carolina, Centro de Estudios Hispánicos e Iberoamericanos, Marcial Pons Historia, 2006.

Portillo Valdés, J. M.: La vida atlántica de Victorián Villava, Madrid, Fundación Mapfre, Doce Calles, 2009a.

Portillo Valdés, J. M.: «Ex unum, pluribus: Revoluciones constitucionales y disgregación de las monarquías iberoamericanas», en Fernández Sebastián, J. (dir.), Diccionario político y social del mundo iberoamericano, Madrid, Fundación Carolina, Sociedad Estatal de Conmemoraciones Culturales, CEPC, 2009b, 307-324.

Roca, J.: 1809. La revolución de la Audiencia de Charcas en Chuquisaca y La Paz, La Paz, Plural, 1998.

Serulnikov, S.: La Revolución de los Andes. La era de Túpac Amaru, Buenos Aires, Sudamericana, 2010. 
Ternavasio, M.: Historia de la Argentina. 1806-1852, Buenos Aires, Siglo Veintiuno, 2009.

Thibaud, C.: La Academia Carolina y la independencia de América. Los abogados de Chuquisaca (1776-1809), Sucre, Editorial Charcas, Fundación Cultural del Banco Central de Bolivia, Archivo y Biblioteca Nacionales de Bolivia, 2010.

Torrico Panozo, V.: El pasquín en la independencia del Alto Perú, México, Plaza y Valdés, 1997.

Walker, Charles: De Túpac Amaru a Gamarra: Cusco y la formación del Perú republicano, 1780-1840, Cusco, CBC, 1999. 